\title{
Time Trends Analysis of Characteristics of Patients with Thyroid Cancer in a Single Medical Center
}

\author{
Hyung Seo Jung, ${ }^{1}$ Min Ji Jeon ${ }^{2}$, Dong Eun Song ${ }^{3}$, Suck Joon Hong ${ }^{4}$, \\ Won Gu Kim², Tae Yong Kim², Young Kee Shong ${ }^{2}$ and Won Bae Kim ${ }^{2}$ \\ University of Ulsan College of Medicine ${ }^{1}$, Division of Endocrinology E Metabolism, Department of Internal Medicine ${ }^{2}$, Department \\ of Pathology ${ }^{3}$, Department of Surgery ${ }^{4}$, Asan Medical Center, Seoul, Korea
}

Background and Objectives: The incidence of thyroid cancer is increasing worldwide. The increase in the frequency of screening tests may have led to an over-detection of small thyroid cancers. The Korean Thyroid Association (KTA) discourages the find needle aspiration of thyroid nodules $\leq 0.5 \mathrm{~cm}$. The aim of this study was to evaluate time trends of characteristics of thyroid cancer patients in a single medical center. Materials and Methods: This study included 15,465 patients who underwent operation due to thyroid cancer from 1995 to 2012. Data on age, gender of patients and histology, clinical stage of the thyroid cancer were reviewed retrospectively. Results: New thyroid cancer cases have dramatically increased and papillary thyroid carcinoma (PTC) accounted for a major part of this increase. PTCs were accounted for $98 \%$ of all thyroid cancer surgeries in 2012 and $79 \%$ in 1995. The proportion of PTCs $\leq 0.5 \mathrm{~cm}$ has increased from 1\% in 1995 to $32 \%$ in 2009 and then slightly decreased afterward. The peak age of patients with PTC has increased from 40 years in 1995-2000 to 55 years in 2006-2012. The proportion of small follicular thyroid carcinomas and medullary thyroid carcinomas $(\leq 1.0 \mathrm{~cm})$ also steadily increased during study periods. Conclusion: Thyroid cancers became smaller but, increase of very small PTCs stopped after 2010, in which the KTA guidelines were introduced. These findings suggest that the increasing incidence of thyroid cancer in Korea might be due to the over-detection of small thyroid cancers.

Key Words: Trends, Thyroid neoplasm, Epidemiology

\section{Introduction}

The incidence of thyroid cancer is on the sharp rise globally and also in Korea. ${ }^{1-6)}$ The well-known risk factors for thyroid cancer are exposure to ionizing radiation, a history of benign thyroid tumor, and a family history of thyroid cancer. ${ }^{7-8)}$ However, the cause of this global trend for increasing thyroid cancer remains unknown.
With the development of diagnostic technology, especially high-resolution ultrasonography (US), it has become possible to detect small thyroid cancers that were previously undetectable. Many small silent thyroid cancers may be diagnosed consequent to the increase in the frequency of thyroid cancer screening tests ${ }^{1)}$ and the incidence of microcarcinomas have increased, indeed. ${ }^{1,9)}$ As a result, the Korean Thyroid Association (KTA) revised the guidelines for thyroid nodule and cancer diagnosis in 2010 and proposed that fine

Received June 24, 2014 / Revised lst October 13, 2014, 2nd October 20, 2014 / Accepted October 23, 20l4 Correspondence: Min Ji Jeon, MD, Division of Endocrinology \& Metabolism, Department of Internal Medicine, Asan Medical Center, 88, Olympic-ro 43-gil, Songpa-gu, Seoul 138-736, Korea

Tel: 82-2-3010-1317,Fax: 82-2-3010-6962,E-mail: mj080332@gmail.com

Bukwang/Dalim Award from the Korean Thyroid Association, 2013

Copyright (c) 2014, the Korean Thyroid Association. All rights reserved.

() This is an open-access article distributed under the terms of the Creative Commons Attribution Non-Commercial License (http:// creativecommons.org/licenses/by-nc/3.0/), which permits unrestricted non-commercial use, distribution, and reproduction in any medium, provided the original work is properly cited. 
needle aspiration cytology (FNAC) would be performed for nodules over $0.5 \mathrm{~cm}$ if patients have risk factors of thyroid cancer or malignant features on US. ${ }^{10)}$ Nevertheless, a recent report using the Korea Central Cancer Registry and the Korea National Cancer Incidence Database data demonstrated that thyroid cancer was the most common cancer on 2011 in Korea. ${ }^{6)}$ However, little has been reported about the recent time trends in thyroid cancer according to pathologic characteristics in Korea.

The aim of this study was to evaluate time trends in the characteristics of thyroid cancer patients between 1995 and 2012 in a single center with comprehensive analysis of pathologic data.

A

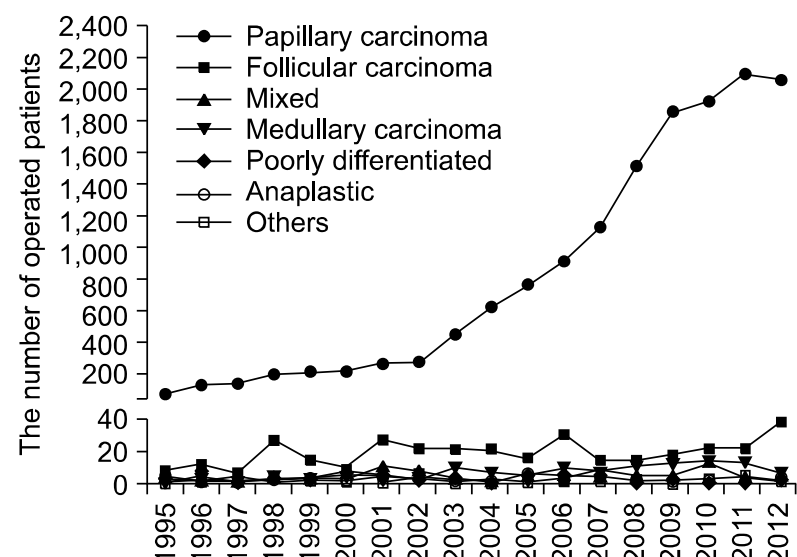

\section{Materials and Methods}

\section{Patients}

This study included 15,465 patients who were diagnosed with thyroid cancer and underwent initial surgery at the Asan Medical Center between 1995 and 2012. Data on age, gender of patients and histological type, clinical stage of the thyroid cancer were retrieved and reviewed retrospectively. Clincopathological data are analyzed according to the year of operation. This study was approved by the Institutional Review Board of Asan Medical Center.

\section{Definitions}

Pathologic types of thyroid cancer were categorized into papillary thyroid carcinoma (PTC), follicular thyroid carcinoma (FTC), medullary thyroid carcinoma (MTC),

B

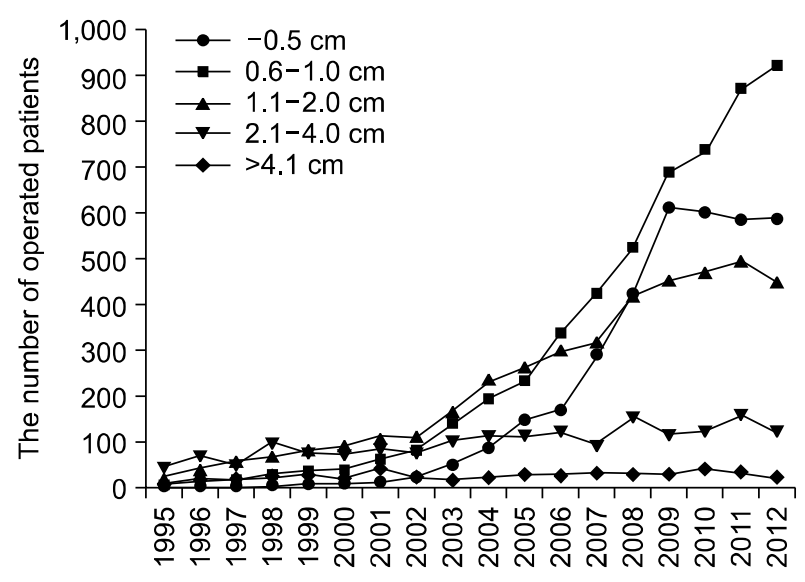

C

\begin{tabular}{|l|c|c|c|c|c|c|c|c|c|c|c|c|c|c|c|c|c|c|}
\hline & 1995 & 1996 & 1997 & 1998 & 1999 & 2000 & 2001 & 2002 & 2003 & 2004 & 2005 & 2006 & 2007 & 2008 & 2009 & 2010 & 2011 & 2012 \\
\hline$-0.5 \mathrm{~cm}$ & 1.1 & 2.0 & 2.6 & 2.6 & 3.0 & 4.2 & 4.1 & 6.5 & 11.0 & 14.0 & 19.0 & 17.8 & 25.3 & 27.5 & 32.3 & 30.4 & 27.3 & 27.9 \\
\hline $0.6-1.0 \mathrm{~cm}$ & 10.1 & 14.4 & 11.9 & 14.2 & 15.8 & 16.7 & 20.1 & 26.2 & 29.5 & 29.5 & 29.5 & 35.3 & 36.3 & 33.7 & 36.2 & 37.3 & 40.6 & 43.7 \\
\hline $1.1-2.0 \mathrm{~cm}$ & 27.0 & 26.8 & 39.1 & 30.6 & 35.5 & 38.8 & 34.9 & 35.2 & 34.4 & 35.9 & 33.2 & 30.9 & 27.3 & 26.9 & 23.9 & 23.9 & 23.1 & 21.5 \\
\hline $2.1-4.0 \mathrm{~cm}$ & 50.6 & 46.4 & 33.1 & 42.2 & 32.9 & 30.8 & 27.4 & 24.6 & 21.4 & 17.0 & 14.6 & 12.8 & 8.2 & 9.9 & 6.1 & 6.2 & 7.3 & 5.9 \\
\hline$>4.1 \mathrm{~cm}$ & 11.2 & 10.5 & 13.2 & 10.3 & 12.8 & 9.6 & 13.5 & 7.5 & 3.7 & 3.5 & 3.8 & 3.1 & 2.8 & 1.9 & 1.5 & 2.1 & 1.6 & 1.0 \\
\hline
\end{tabular}

Fig. 1. Time trends of the thyroid cancers. (A) Changes in the number of thyroid cancer patients according to their pathology type. (B) Changes in the number of papillary thyroid carcinoma patients according to their primary tumor size. (C) Changes in the proportion of papillary thyroid carcinoma patients according to their primary tumor size. The number in this table presented the percentage of patients in each year. 
poorly differentiated thyroid carcinoma (PDTC), anaplastic thyroid carcinoma (ATC).

Microscopic invasion was defined as extension to the sternothyroid muscle or perithyroidal soft tissues. ${ }^{11)}$ Primary tumors without invasion of surrounding tissue beyond the thyroid capsule regarded as having no perithyroidal extension. The clinical stage of thyroid cancer was classified according to the 6th edition of Tumor Node Metastasis (TNM) staging system of the American Joint Committee on Cancer/International Union against Cancer. ${ }^{11)}$

\section{Methods}

$R$ version 3.0.1 and $R$ library Cairo were used for data analysis and graph creation ( $R$ Foundation for Statistical Computing, Vienna, Austria, and http://www.R-project.org).

A

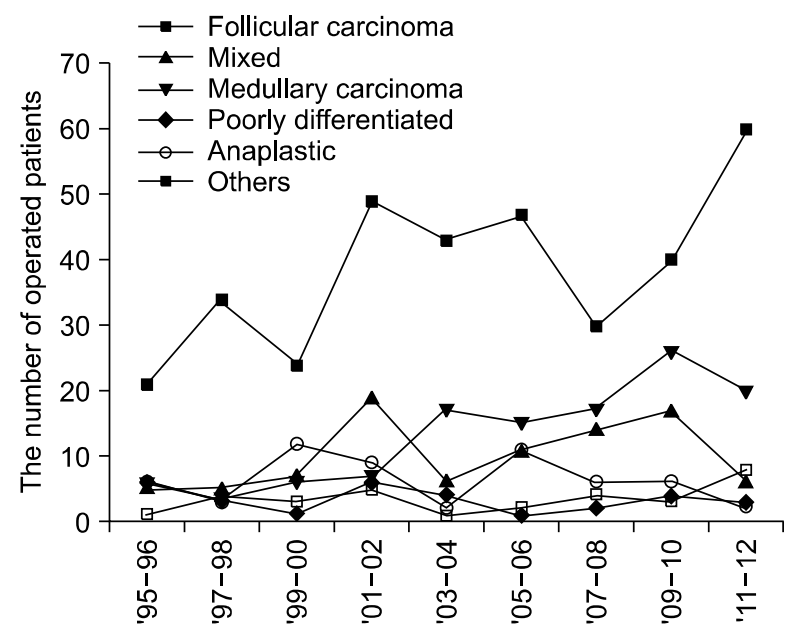

C

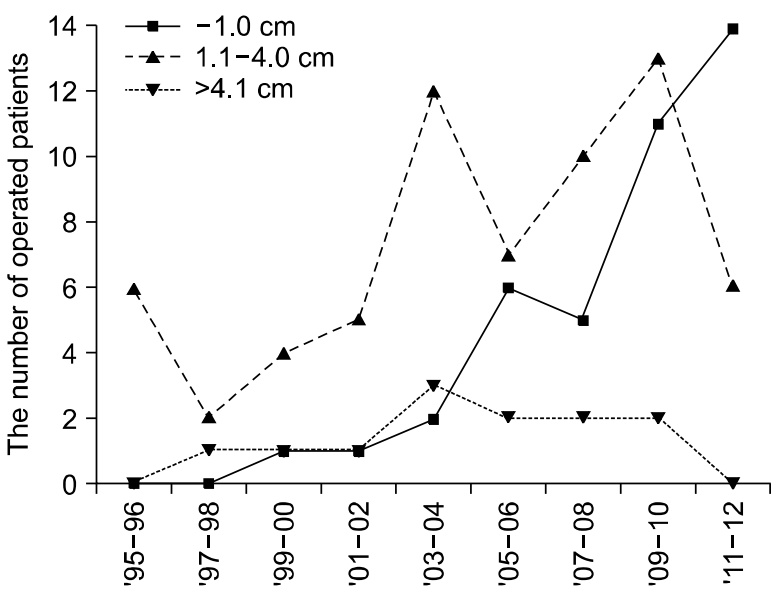

The number of patients or the proportion of patients according to variable characteristics and the year of operation was presented. The comparison of age according to the year of operation was done using analysis of variance (ANOVA) test.

\section{Results}

\section{Baseline Characteristics}

Of 15,465 patients, 12,678 (82\%) patients were female, 2787 (18\%) patients were male. The proportion of male has increased $11 \%$ in 1995 to $21 \%$ in 2012 . 14,798 (96\%) patients were diagnosed with PTC and 343 (2\%) were diagnosed with FTC. One hundred and seventeen patients had MTC, 89 had PTC combined
B

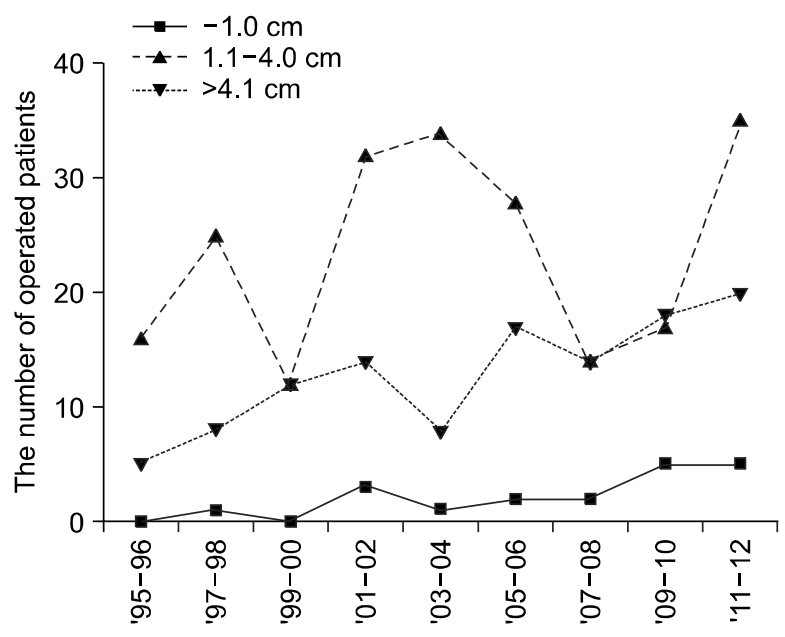

Fig. 2. Time trends in the number of thyroid cancer patients except papillary thyroid carcinoma. (A) Changes in the number of thyroid cancer patients except papillary thyroid carcinoma according to their pathology type. (B) Changes in the number of follicular thyroid carcinoma patients according to their primary tumor size. (C) Changes in the number of medullary thyroid carcinoma patients according to their primary tumor size. 
with FTC, 57 had ATC, 30 had PDTC, and 31 had other histological types.

\section{Time Trends of Pathology Distribution}

The number of thyroid cancer has increased 23.7 fold from 89 in 1995 to 2105 in 2012. PTCs accounted for a major part of this increase. The number of PTC cases has increase 29.3 fold from 70 in 1995 to 2054 in 2012. PTCs were accounted for $98 \%$ of all thyroid cancer surgeries in 2012 and 79\% in 1995 (Fig. 1A). The number of FTC and MTC patients has also increased but, the proportion of those patients were decreased (Figs. 1A, 2A).

\section{Time Trends of Primary Tumor Size}

The number and proportion of PTCs $\leq 0.5 \mathrm{~cm}$ in-

\section{A}

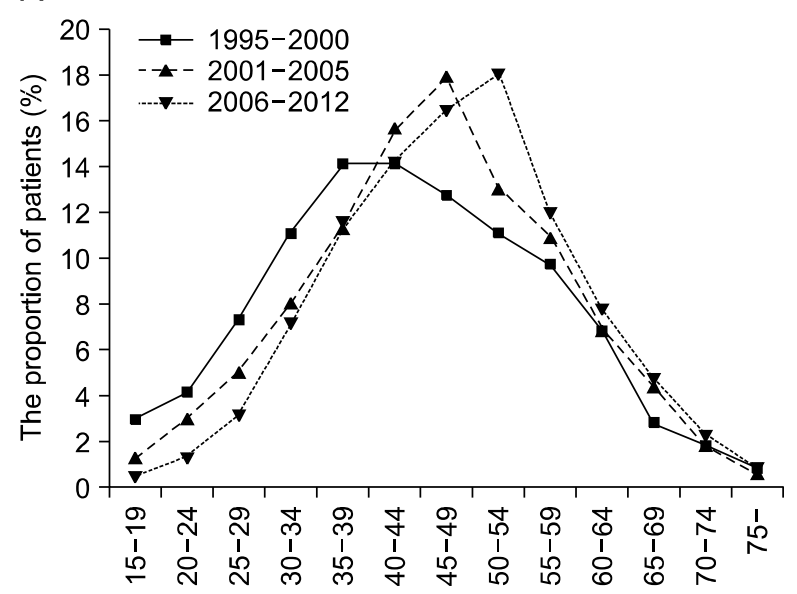

C

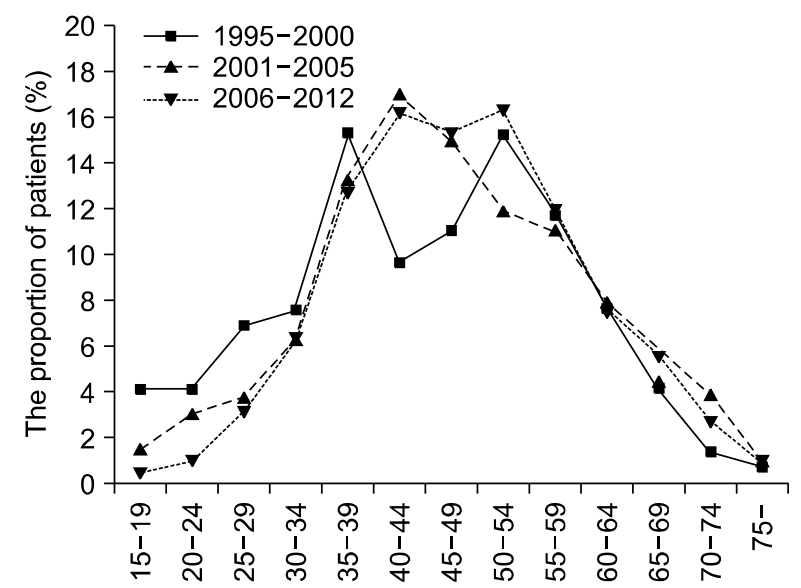

creased prominently until 2009, slightly decreased and plateaued from 2010 onward (Fig. 1B); those of PTCs $>0.5 \mathrm{~cm}$ and $\leq 1 \mathrm{~cm}$ showed a continuous, sharp increase and accounted for 44\% of PTCS in 2012; and the proportion of PTCs $>1.0 \mathrm{~cm}$ and $<2 \mathrm{~cm}$ fluctuated. The number of PTCs larger than $2.0 \mathrm{~cm}$ remained constant during study periods but, the proportion of PTCs larger than $2.0 \mathrm{~cm}$ showed sharp decreased from 62\% in 1995 to $7 \%$ in 2012 (Fig. 1C).

The number of FTCs $\leq 1.0$ slightly increased and the proportion of them also slightly increased from $0 \%$ in 1995-1996 to 8\% in 2011-2012 (Fig. 2B). The number of MTCs $\leq 4.0 \mathrm{~cm}$, especially that of $\leq 1.0 \mathrm{~cm}$, increased prominently, and the proportion of MTCs $\leq$ $1.0 \mathrm{~cm}$ was $70 \%$ in 2011-2012 (Fig. 2C).

B

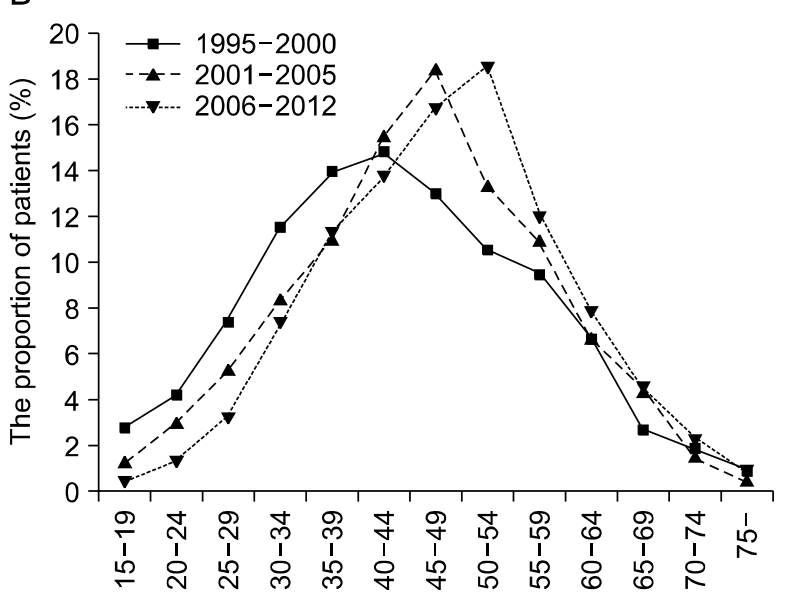

Fig. 3. Time trends in the age of thyroid cancer patients. The $X$ axis represents the age of patients and the $Y$ axis represents the percentage of patients. Patients were classified into 3 groups according to their year of operation; 1995-2000, 2001-2005 and 2006-2012. (A) Overall patients. (B) Female. (C) Male. 


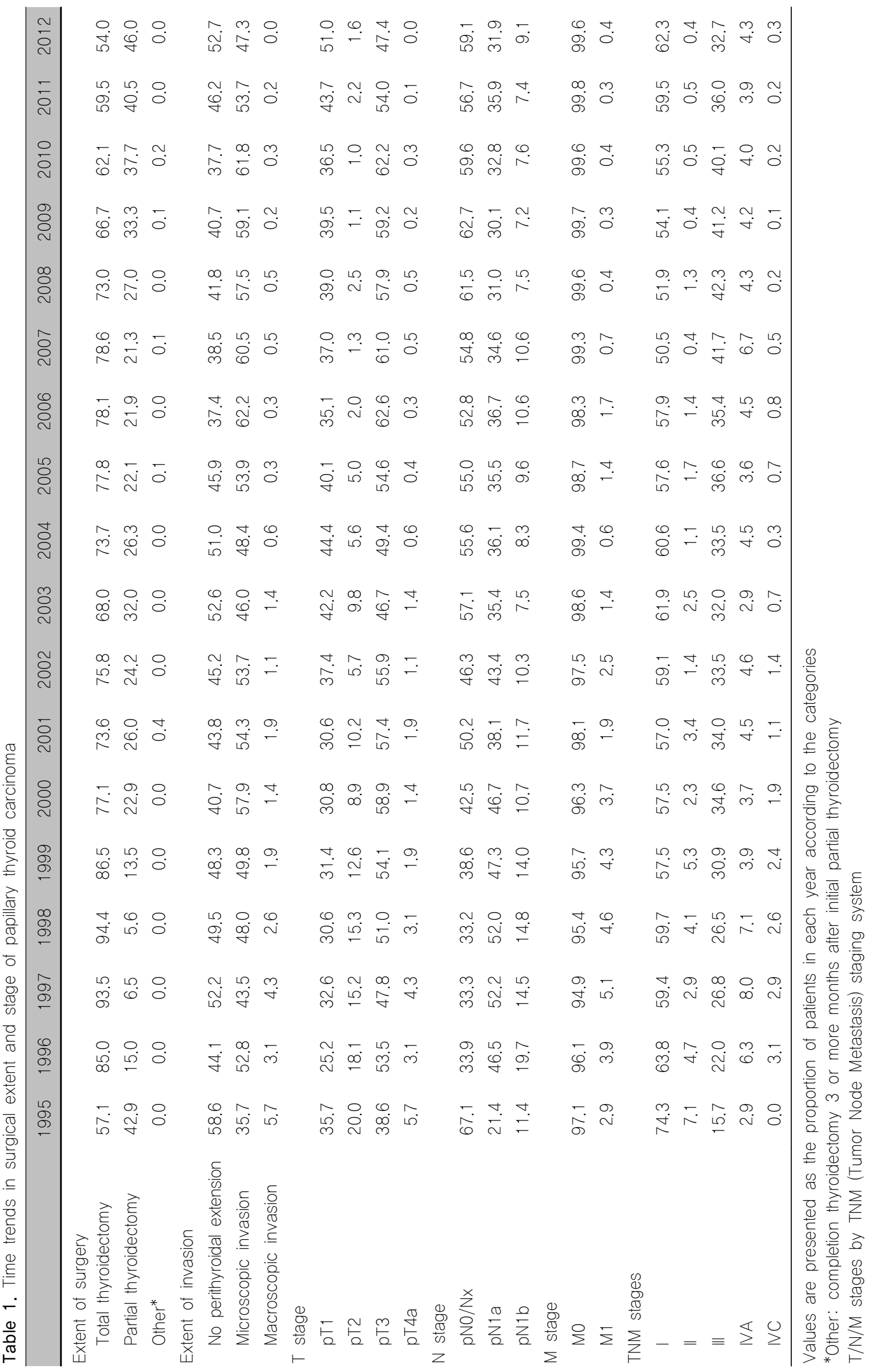




\section{Time Trends of Age Distribution in PTC}

The peak age at diagnosis was 40 years in 1995-2000, which increased to 50 years in 2006-2012 (Fig. 3A). The mean age at diagnosis has also increased over time and this trend was statistically significant using ANOVA analysis $(p<0.001)$. With regard to sex distribution, the age at diagnosis increased from 40 years in 1995-2000 to 55 years in 2006-2012 in female patients and increased from 35 years in 1995-2000 to 45 years in 2006-2012 in male patients (Fig. 3B, C).

\section{Time Trends in Surgical Extent and Stage of PTC (Table 1)}

The proportion of total thyroidectomy including completion thyroidectomy among PTC cases increased from 1995 to 1998, fluctuated afterward and steadily decreased since 2007. The proportion of PTC patients who underwent partial thyroidectomy has changed oppositely.

The proportion of PTC cases with macroscopic invasion steadily decreased and those with microscopic invasion have slightly increased until 2010 with wax and wane pattern and decreased afterward. The proportion of intra-thyroidal PTC cases also showed fluctuation.

The proportion of PT1 PTCs is increasing continuously and that of PT3 PTCs increased until 2010 and then decreased. Even though primary tumors became smaller, the prevalence of lymph node (LN) metastases was increased from 33\% in 1995 to $41 \%$ in 2012. The proportion of pN1a according to TNM staging system cases markedly increased from 1995 to 2000 and remained constant afterward. The number of pN1b cases according to TNM staging system has decreased until 2008 but remained constant afterward. The proportion of PTCs with distant metastasis has significantly decreased with some fluctuations.

Overall, the proportion of stage I cases slightly decreased whereas that of stage III cases prominently increased until 2009, and has been on the decline since 2010. The proportion of stage \| and IVC cases significantly decreased and that of stage IVA remained constant.

\section{Discussion}

Our study presented recent time trends of the characteristics of thyroid cancer in a large patient population. The new thyroid cancers have dramatically increased from 1995 to 2012 and PTCs, especially $\leq$ $1 \mathrm{~cm}$ PTCs, accounted for a major part of this increase. These are consistent with previous reports. ${ }^{1,6,9}$ However, the number and proportion of PTCs $\leq 0.5 \mathrm{~cm}$ decreased and plateaued since 2010. It could not be natural and might be affected by the revised KTA guidelines in 2010 because FNAC is not recommended for small nodules according to this new guideline. Consensus on FNAC for thyroid nodules smaller than $1 \mathrm{~cm}$ has not yet been reached, and various guidelines have different recommendations. ${ }^{11-13)}$ Most thyroid cancers $\leq 0.5 \mathrm{~cm}$ are associated with a favourable prognosis and small nodules often yield inadequate specimens with FNAC; accordingly, the 2010 revised Thyroid Nodule and Cancer Diagnostic Guidelines of the KTA recommended FNAC for nodules $>0.5 \mathrm{~cm}$ if the patient belongs to a high-risk group or if malignant features are detected on US. ${ }^{10)}$

The exact cause of the sharp increase in thyroid cancer is still uncertain and the widespread use of US is the one most important cause. ${ }^{1,14)}$ Our findings, the rapid change in the number of new small thyroid cancer cases following the revision of the guideline, supported the previous report that the increasing thyroid cancer reflected greater detection of subclinical disease due to an increased use of neck US with FNAC." However, recent epidemiologic study revealed that only half of the increase in thyroid cancer is due to the increased use of US and the remaining half may be a true increase of cancer. ${ }^{15)}$ This is supported by the other studies reported that the thyroid cancer incidence seems to be increasing in children, adolescents and young adults and over $2 \mathrm{~cm}$ large-sized cancers are also increasing. ${ }^{16-18)}$ In this study, the number of large thyroid cancers was also not decreased during study periods. Additional studies are needed to investigate environmental, dietary, and genetic factors that might cause the increase of thyroid cancer. 
Of note, the proportion of stage NA cases with pN1b disease remained constant despite most of cancers are microcarcinomas. Lateral cervical LN involvements are associated with the high risk of recurrence or distant metastasis of PTC. ${ }^{19,20)}$ However, recent preoperative neck US also detects small, subclinical metastatic LNs and these are known to have better prognosis. ${ }^{21)}$ We could not analyze the prognosis of patients in this study but, another study of our group identified that the size and the number of metastatic LNs were significantly decreased with the improvement of prognosis over time. It is unclear whether early diagnosis and treatment of thyroid cancers improve survival. However, neck US has led to the detection of earlier stage disease with smaller tumors and LNs, and might improve patient outcome in terms of recurrence. Therefore, the proper application of neck US and FNAC according to the guideline is needed and it might lead to the decrease in over-detection of subclinical cancers.

However, still 30\% of new PTCs were equal or smaller than $0.5 \mathrm{~cm}$ since 2010 . The possible reasons for the plateau rather than a prominent decline in the number of PTCs $\leq 0.5 \mathrm{~cm}$ as follow. First, the nodule size on US usually is larger than that measured after formalin fixation of the sample. Although the nodule may appear $>0.5 \mathrm{~cm}$ on US, its size may be smaller after excision and formalin fixation for pathological examination. Second, the revised guidelines recommend FNAC in cases of cervical $L N$ involvement regardless of the nodule size. Third, microcarcinomas could be incidentally found from surgical specimens of the clinically benign large thyroid nodule.

Surprisingly, the age at diagnosis of thyroid cancer was 40 years in 1995-2000 and increased to 55 years in 2006-2012 in this study. The age at diagnosis increased even when male and female patients were analyzed separately. Although the cause of the increase in the age at diagnosis is still unclear, this finding is consistent with previous reports from Cho et al. ${ }^{9)}$ This phenomenon might be explained by the fact that the age at diagnosis increased with the increase in the age of patients exposed to the certain risk factor.

The present study is limited in its retrospective design.
We could not analyze the changes in disease outcome. As well, we only included patients who underwent initial surgical treatment for thyroid cancer at a single institution. They might not be representative of all patients with thyroid cancer in Korea and the result from them might be biased. Further nation-wide or multicenter research is required supporting our findings.

In conclusion, thyroid cancers became smaller but, increase of very small PTCs, $\leq 0.5 \mathrm{~cm}$ stopped after the revised KTA guidelines were introduced. These findings suggest that the increasing incidence of thyroid cancer in Korea might be due to the over-detection of small thyroid cancers. The proper application of neck US and FNAC according to the guideline is needed.

\section{References}

1) Davies L, Welch HG. Increasing incidence of thyroid cancer in the United States, 1973-2002. JAMA 2006;295(18):2164-7.

2) Leenhardt L, Grosclaude P, Cherie-Challine L. Increased incidence of thyroid carcinoma in france: a true epidemic or thyroid nodule management effects? Report from the French Thyroid Cancer Committee. Thyroid 2004;14(12):1056-60.

3) Liu S, Semenciw R, Ugnat AM, Mao Y. Increasing thyroid cancer incidence in Canada, 1970-1996: time trends and ageperiod-cohort effects. Br J Cancer 2001;85(9):1335-9.

4) Reynolds RM, Weir J, Stockton DL, Brewster DH, Sandeep TC, Strachan MW. Changing trends in incidence and mortality of thyroid cancer in Scotland. Clin Endocrinol (Oxf) 2005;62(2): 156-62.

5) Smailyte G, Miseikyte-Kaubriene E, Kurtinaitis J. Increasing thyroid cancer incidence in Lithuania in 1978-2003. BMC Cancer 2006;6:284.

6) Jung KW, Won YJ, Kong HJ, Oh CM, Lee DH, Lee JS. Cancer statistics in Korea: incidence, mortality, survival, and prevalence in 2011. Cancer Res Treat 2014;46(2):109-23.

7) Iribarren C, Haselkorn T, Tekawa IS, Friedman GD. Cohort study of thyroid cancer in a San Francisco Bay area population. Int J Cancer 2001;93(5):745-50.

8) Ron E, Kleinerman RA, Boice JD Jr, LiVolsi VA, Flannery JT, Fraumeni JF Jr. A population-based case-control study of thyroid cancer. J Natl Cancer Inst 1987;79(1):1-12.

9) Cho BY, Choi HS, Park YJ, Lim JA, Ahn HY, Lee EK, et al. Changes in the clinicopathological characteristics and outcomes of thyroid cancer in Korea over the past four decades. Thyroid 2013;23(7):797-804.

10) Yi KH, Park YJ, Koong SS, Kim JH, Na DG, Ryu JS, et al. Revised Korean Thyroid Association management guidelines for patients with thyroid nodules and thyroid cancer. Endocrinol Metab 2010;25(4):270-97. 
11) American Thyroid Association (ATA) Guidelines Taskforce on Thyroid Nodules and Differentiated Thyroid Cancer, Cooper DS, Doherty GM, Haugen BR, Kloos RT, Lee SL, et al. Revised American Thyroid Association management guidelines for patients with thyroid nodules and differentiated thyroid cancer. Thyroid 2009;19(11):1167-214.

12) Camargo R, Corigliano S, Friguglietti C, Gauna A, Harach $\mathrm{R}$, Munizaga $\mathrm{F}$, et al. Latin American thyroid society recommendations for the management of thyroid nodules. Arq Bras Endocrinol Metabol 2009;53(9):1167-75.

13) Gharib H, Papini E, Paschke R, Duick DS, Valcavi R, Hegedus L, et al. American Association of Clinical Endocrinologists, Associazione Medici Endocrinologi, and European Thyroid Association medical guidelines for clinical practice for the diagnosis and management of thyroid nodules. endocr Pract 2010;16 Suppl 1:1-43.

14) Davies L, Welch HG. Current thyroid cancer trends in the United States. JAMA Otolaryngol Head Neck Surg 2014;140(4):317-22.

15) Udelsman R, Zhang Y. The epidemic of thyroid cancer in the United States: the role of endocrinologists and ultrasounds. Thyroid 2014;24(3):472-9.

16) Moon EK, Park HJ, Oh CM, Jung KW, Shin HY, Park BK, et al. Cancer incidence and survival among adolescents and young adults in Korea. PLoS One 2014;9(5):e96088.

17) Park S, Jeong JS, Ryu HR, Lee CR, Park JH, Kang SW, et al. Differentiated thyroid carcinoma of children and adolescents: 27-year experience in the yonsei university health system. J Korean Med Sci 2013;28(5):693-9.

18) Vergamini LB, Frazier AL, Abrantes FL, Ribeiro KB, Rodriguez-Galindo C. Increase in the incidence of differentiated thyroid carcinoma in children, adolescents, and young adults: a population-based study. J Pediatr 2014;164(6):1481-5.

19) Grebe SK, Hay ID. Thyroid cancer nodal metastases: biologic significance and therapeutic considerations. Surg Oncol Clin N Am 1996;5(1):43-63.

20) Machens A, Hinze R, Thomusch O, Dralle H. Pattern of nodal metastasis for primary and reoperative thyroid cancer. World J Surg 2002;26(1):22-8.

21) Randolph GW, Duh QY, Heller KS, LiVolsi VA, Mandel SJ, Steward DL, et al. The prognostic significance of nodal metastases from papillary thyroid carcinoma can be stratified based on the size and number of metastatic lymph nodes, as well as the presence of extranodal extension. Thyroid 2012;22(11):1144-52. 